See discussions, stats, and author profiles for this publication at: https://www.researchgate.net/publication/232812371

\title{
Hand hygiene compliance: Is there a theory-practice-ethics gap?
}

Article in British journal of nursing (Mark Allen Publishing) · September 2012

DOl: 10.12968/bjon.2012.21.17.1011 · Source: PubMed

CITATIONS

6

1 author:

Manfred Mortell

University of Malaysia Sarawak UNIMAS

15 PUBLICATIONS 31 CitATIONS

SEE PROFILE

Some of the authors of this publication are also working on these related projects:

Perceptions of Malaysian families and healthcare professionals in Sarawak regarding family presence during resuscitation: A cross sectional study View project
READS

320 


\section{Hand hygiene compliance: is there a theory-practice-ethics gap? \\ Manfred Mortell}

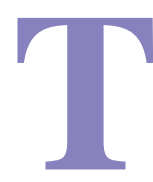

he origins of hand hygiene and the empirical use of disinfectants date back to as early as $800 \mathrm{BC}$, when

Homer reported the use of sulphur as a disinfectant in The Odyssey.

The evolution continued with the discovery of chlorine in 1774 by Scheele, a Swedish chemist. In 1825, Labarraque, a French pharmacist, advocated the use of calcium hypochlorite for general sanitation, which included hand hygiene, in hospital wards.

The late 19th century ushered in the acceptance of Louis Pasteur's germ theory of infection, which started infection control practices that were the genesis of evidencebased practice (Block, 1991).

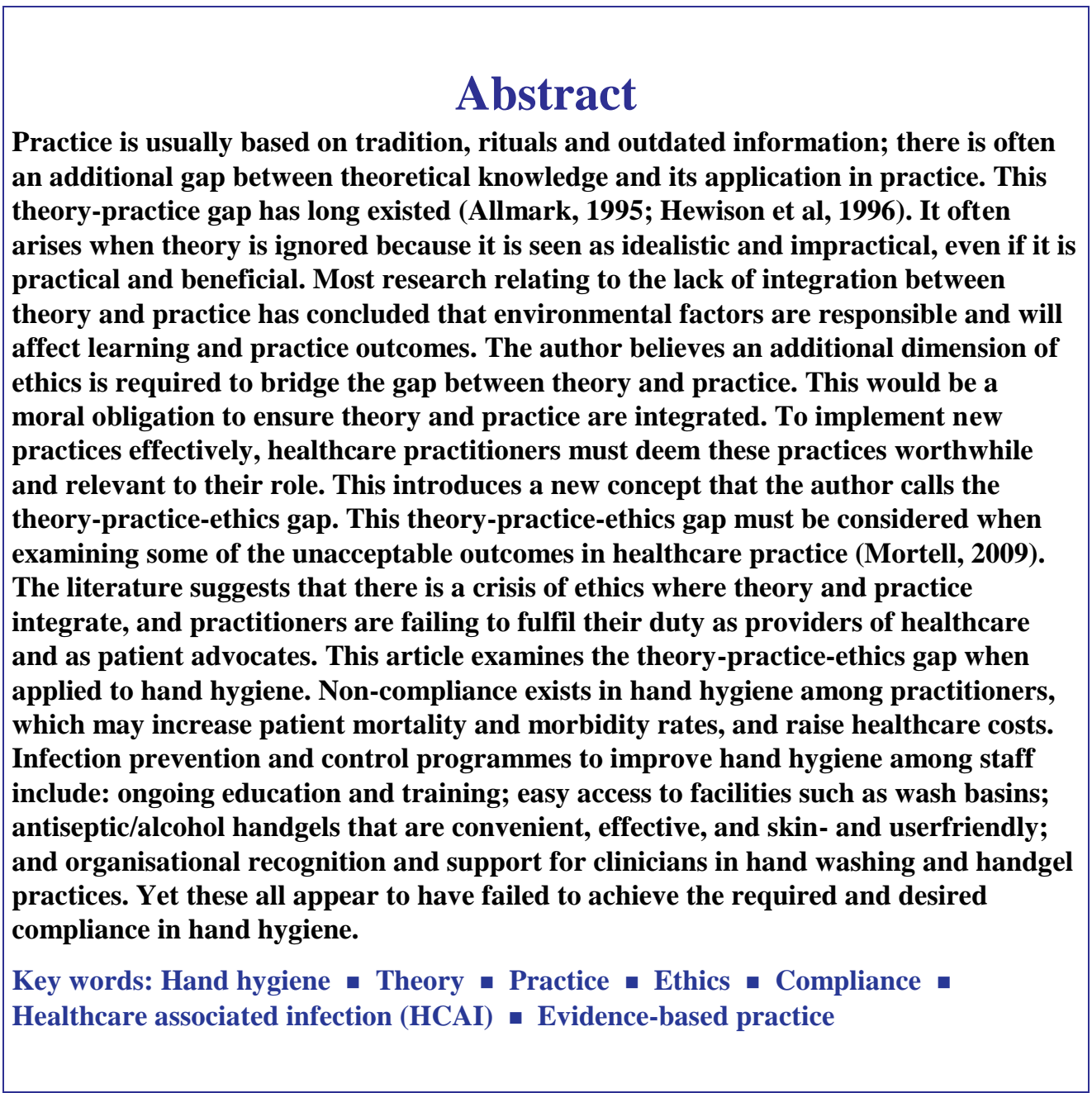

